地 24 巻 $\stackrel{\text { 震 }}{\text { 第 } 2 \text { 輯 }}$

\title{
割れ目伝播の停止機構
}

\author{
東京大学理学部地球物理学教室 菊地正幸・竹内 均 \\ (昭和 46 年 8 月 25 日受理)
}

\section{Stop Mechanism of Crack Propagation}

\author{
Masayuki KIKUCHI and Hitoshi TAKEUCHI \\ Geophysical Institute, Faculty of Science, \\ University of Tokyo
}

(Received August 25, 1971)

\begin{abstract}
In a previous paper, it was shown that a crack, with the initial length longer than a critical one, can propagate in an elastic medium with the crack velocity which approaches asymptotically to the $\mathrm{S}$ wave velocity in the medium. The next problem is how to stop the crack propagation thus acceralated. A way to do this is to assume the pre-stress in the medium is limited to a region, from $-x_{m}$ to $+x_{m}$, say, where $x$ is in the direction of crack propagation. This problem is studied in the present paper and we get the following results. (1) crack does not stop at once even when it passes through $x=x_{m}$ (Fig. 4, 5, 6). (2) Final crack length $c_{s}$ is about twice as long as $x_{m}$ (Fig. 7). (3) The longer the length $x_{m}$, the larger the mean velocity of the crack (Fig. 8).
\end{abstract}

最近の地震学的研究によると，地震の際の破壊は全長にわたつて一度におこるのではなく， $\mathrm{S}$ 波の速度に近い速さで伸びていくといらことが知られている，われわれは，応力ドロップに よつて解放される弾性エネルギーが割れ目の先端に集中していくという考光と，運動論的に拡 張されたグリフィスの破壊条件の二つをくみ合わることによつて，この現象の具体的なからく りを理論的に明らかにした。そして，同時に，運動論的な場合の割れ目の発展条件についても 論じた. (1971) 。

割れ目の伝播に関する一連の理論的研究の中での次の課題は, 爆発的進行から減速過程への 移行，および，停止の機構を明らかにすることである。このような問題は，これまで，実験的 にも理論的にもほとんどとりあげられてこなかつた。 したがつて，これを理論的に追求してい く場合，さしあたりは，考学れれいくつかの物理条件について，これまでの理論を拡張して いく形で始めなければならない。

そのために，まず，割れ目の伝播に関するこれまでのすべての理論に共通している二つの要

昭和 46 年 5 月 20 日, 地震学会にて発表. 
因を明らかにしておく必要がある，その一つは，割れ目進行の推進力であり，もう一つは，進 行を妨げる力である，割れ目の発展条件，および，爆発的進行過程は，前者の後者に対する相 対的増加によつて，また減速過程，および，停止条件への移行は，後者の前者に対する相対的 増加によつて可能となる，われわれが展開してきた理論に打いては，推進力は応力ドロップに よる弾性エネルギーの解放であり，抑止力は割れ目による表面エネルギーの増加，および，割 れ目の両端の相互作用である。したがつて, 割れ目の進行が減速される物理的条件としては, 次のようなことが考えられる。

（1）最初の応力の分布が有限範囲に限られている

（2）分枝の形成によつて表面エネルギーが増加し，また，各分枝の先端で相互作用 が起こる

（3）空間的に破壊強度が增す

もちろん, これらの複合条件も可能である. しかし, 当面は, (1), (2), (3) のおのおのに ついて独立に問題を設定し，それぞれの解の特徵を明らかにすることから始めなければならな い.以下，この論文の目的は，上記のような課題への最初の試みとして，(1) の場合について 調ベることである。

$\mathrm{SH}$ 型割れ目の伝播について考光る (Fig. 1). 最初の割れ目の長さを $2 c, z=0$ の面上での 応力 $\tau_{y z}(x)$ を

$$
\tau_{y z}(x)=\left\{\begin{array}{lll}
\tau_{0} & \text { for } & |x| \leq x_{m} \\
0 & \text { for } & |x|>x_{m}
\end{array}\right.
$$

とする。すすおち，割れ目の長さが $2 x_{m}$ より短い範囲では応力ドロップが起こるが，それを こえると割れ目ができても応力ドロップは起こらない とする，以下，剛性率を $\mu, S$ 波の速度を $V_{s}$ とし， $t_{0}=\pi \mu T / 2 \tau_{0}^{2} V_{s}$ と定義して括く。をた, 時間の単位, および，長さの単位をそれぞれ $t_{0}, t_{0} V_{s}$ とする場合に は各記号の上に波型のしるしを付けて表わす。

割れ目の進行を時間的に和つていくと，次のような 各段階がある (Fig. 2).

(1) 割れ目が動き出す時刻 $t_{0}$.

（2）割れ目の左端 $x_{1}(0)$ の影響が右端に利 達する時刻 $t_{1}$.

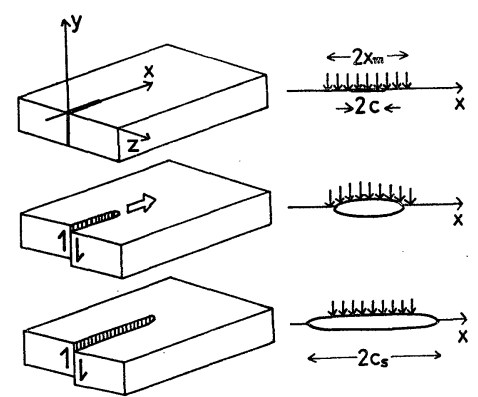

Fig. 1. Crack propagates along the $x$-axis. Displacement vector has $y$-component only. $c$ and $c_{s}$ are initial and final crack length, respectively. 
（3）左端が動きはじめたこと（すなわち， $\left.x_{1}\left(t_{0}\right)\right)$ の影響が右端に利達する時刻 $t_{2}$.

（4） $x_{2}(0)$ の影響が左端で反射し，再び右端に打いつく時刻 $t_{3}$.

以下同様にして, $t_{4}, t_{5}, \cdots$

ここでは， $t \leq t_{3}$ の場合についてのみ考光る．前回 (1971) に和いて， $t \leq t_{2}$ の場合に限つたのと全く同 じ理由から， $t>t_{3}$ の場合についても， $t_{2} \leq t \leq t_{3}$ に おける計算をそのます用いてほとんどさしつかえな い. また， $t_{3}$ に達する以前に割れ目が止まつてしま ら場合には，それ以後のことはわれわれにとつては 不必要である。このような理由によつて，今回の問 題に括いては， $t \leq t_{3}$ と考㝋ても十分であると考光 たからである。

時刻 $t$ に和ける割れ目の右端 $x_{2}(t)$ の進行速度 $V\left(x_{2}, t\right)$ を求めるためには，次の三つの計算段階を 経なければならない，第一に，応力ドロップによつ

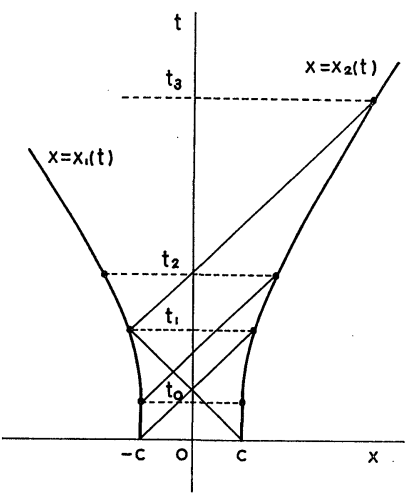

Fig. 2. Crack starts to propagate at time $t=t_{0}$. Effect of the crack's left end at time $t=0$ reaches the right end at time $t=t_{1}$, and so on.

てひきおこされる割れ目の外の応力を求めること. 第二に, 割れ目の先端への応力集中係数 $k\left(x_{2}, t ; V\right)(1971,(1))$ を求めること. 第三に， $k$ と表面エネルギーとの関係，すなわち， 破壊条件 (同，(3)）から $V$ を求めること.

$t \leq t_{3}$ のみを考える場合, 計算上の第一段階である割れ目の外の応力 $\tau_{y z}(x, t)$ は $0<t \leq t_{1}$, $x<x_{1}(t)$ の範囲だけを求めて打けば十分である。時刻 $t^{\prime}$ に打梳左端の外側 $x^{\prime}$ の応力 $\tau_{y z}\left(x^{\prime}, t^{\prime}\right)$ は

$$
\tau_{y z}\left(x^{\prime}, t\right)=\frac{1}{\pi \sqrt{c_{1}-x^{\prime}}} \int_{x^{\prime}+t^{\prime}}^{c_{1}} \frac{\tau_{0} \sqrt{\xi-c_{1}}}{x^{\prime}-\xi} d \xi
$$

によつて求められる $(1971,(10))$. ここで $c_{1}$ は, $x=x_{1}(t)$ と $x=-\left(t-t^{\prime}\right)+x^{\prime}$ との交点の $x$ 座標である (Fig. 3). 前回は $x_{1}(t)=-c$ (一定) の範囲だ けでよかつた。計算上の第二，第三段階は前回と全く同様で あるから省略し，次の二つの点を指摘して抢くにとどめる。 第一に，割れ目の先端 $x_{2}(t)$ が $x_{m}$ をこえても，そのことだ けで, 割れ目の進行が減速過程をたどるとは限らない。なぜ なら，ある瞬間の応力ドロップがただちに割れ目の先端に集 中することは決してなく, 先端との距離を $S$ 波が伝わるの

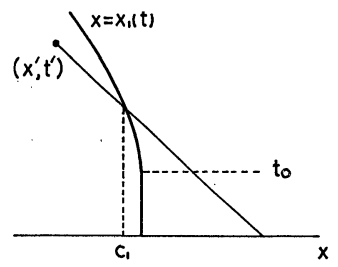

Fig. 3. Schematic figure corresponding to formula (2) . 
に必要な時間だけ遅れて影響するからである. 第二に, 減速の要因のひとつである割れ目の先 端の相互作用は両端間の距離のルートに反比例して弱くなつていくが，このことが，ただち に，この作用を無視できるといらことを意味するものではない。なぜなら，割れ目の進行が減 速されるか否かは，あくまで，推進力と抑止力の相対的な大小によるからである.

割れ目の進行速度の時間的変化を計算した 結果は, Fig. 4, 5, 6 に示してある.一様な 応力ドロップの場合の割れ目の進行はただ一 つのパラメータ $\tilde{c}$ によつてのみ規定される が，有限範囲の応力ドロップの場合には， $\tilde{x}_{m}$ なるパラメタが加わる. Fig. 4,5 は $\tau$ $=1,2$ の場合について， $\tilde{x}_{m}$ が変わることに よつて割れ目の進行の様子がどのように変化 するかを示している. Fig. 6 は逆に, $\tilde{x}_{m}=4$

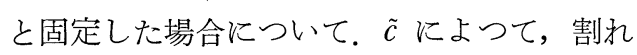
目の進行の様子がどのように変化するかを示 している.

割れ目の先端が $x_{m}$ を通過する時刻と両端 の相互作用がはじまる時刻との相対的前後関 係によつて，伝播の様子は大きく異なる．先

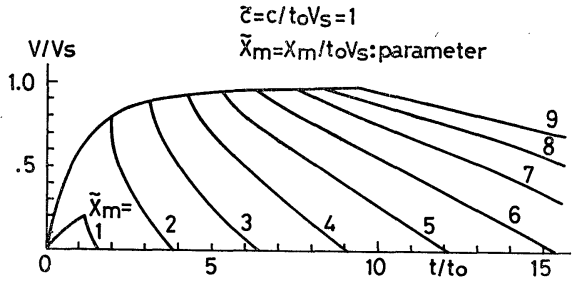

Fig. 4. Fracture velocity variation with the time. Initial crack length is fixed at $c=1$.

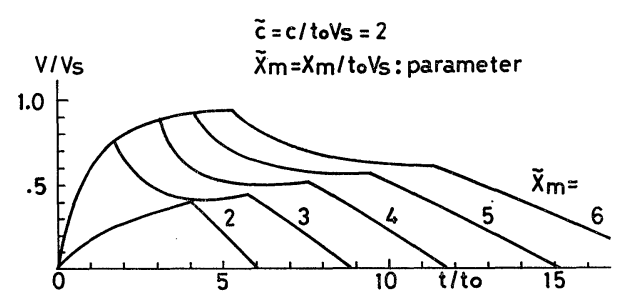

Fig. 5. Fracture velocity variation with the time. Initial crack length is fixed at $c=2$.

端が $x_{m}$ を通過する以前に両端の相互作用が はじまつている場合すなわち， $x_{2}\left(t_{1}\right)<x_{m}$ の 場合）には，割れ目は $x_{m}$ を通過後，単純な 減速過程を続け，やがて止まる (Fig. 4).乙 かし，逆の場合（すなわち， $x_{m}<x_{2}\left(t_{1}\right)$ ) に は，割れ目が $x_{m}$ を通過すると一たんは減速 するが，そのまま単純には減速せず，減速を 弱めるか，あるいは，再び加速される。そし

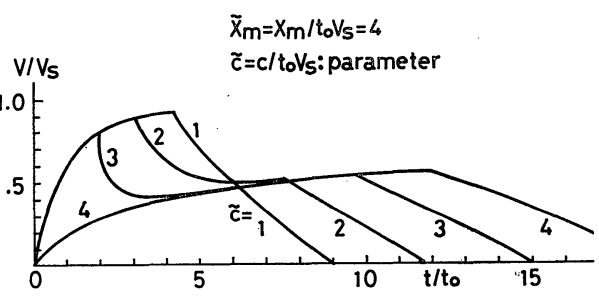

Fig. 6. Fracture velocity variation with the time. The length of the perstress region is fixed at $x_{m}=4$.

て，両端の相互作用がはじまつた後，はじめて単純な減速過程に入り，やがて止まる(Fig.

5). $x_{2}\left(t_{1}\right)=x_{m}\left(=x_{m 0}\right.$ とする $)$ となる点を求めるには， $x_{2}\left(t_{1}\right)<x_{m}$ の場合の $x_{2}\left(t_{1}\right)$ を求 めればよい，この場合には前回の結果をそのまま使える $(1971 ，(8)) . \tilde{t}_{1} ， \tilde{x}_{2}$ を用いて書き直 すと 


$$
\tilde{t}_{1}=\tan \left(\frac{\pi}{4}-\frac{1}{2}+\tilde{c}\right) \tilde{x}_{2}\left(\tilde{t}_{1}\right)=\tilde{t}_{1}-\tilde{c}
$$

となる，ただし， $\tilde{c} \geq 1 / 2+\pi / 4$ のときには， $\tilde{t}_{1}(>0)$ は存在せず，したがつて，他の条件が入 つてこない限り，両端の相互作用は起こらない，結局，割れ目伝播の二つの型の接点を与える $\tilde{x}_{m 0}$ は次のようになる.

$$
\tilde{x}_{m 0}=\tan \left(\frac{\pi}{4}-\frac{1}{2}+\tilde{c}\right) \quad \text { for } \quad \tilde{c}<\frac{1}{2}+\frac{\pi}{4}
$$

いま仮に， $x_{2}\left(t_{1}\right)<x_{m}$ の伝播の型を $A$ 型，他方を $B$ 型とすると，それぞれの型の物理的条 件は

$A$ 型; $\tilde{c}<\frac{1}{2}+\frac{\pi}{4}$, かつ, $\quad x_{m}<x_{m 0}$

$B$ 型; $\tilde{c} \geq \frac{1}{2}+\frac{\pi}{4}$ ，または， $x_{m}>x_{m 0}$

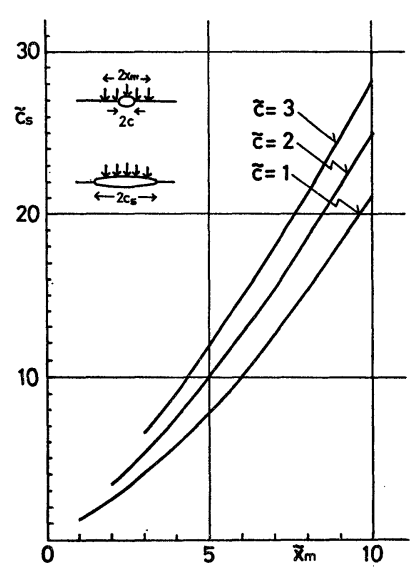

Fig. 7. Final crack length $c_{s}$ and $x_{m}$ with fixed $c$

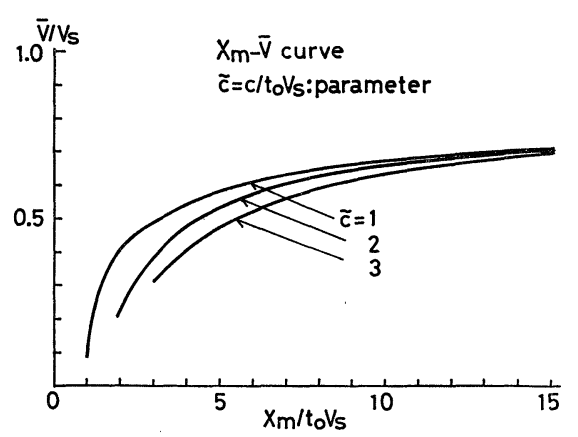

Fig. 8. Mean velocity.

となる。

割れ目が止まつたときの先端の座標を $c_{s}$, 時刻を $t_{s}$ とすると, 割れ目の平均速度 $\bar{V}$ は

$$
V=\frac{c_{s}-c}{t_{s}-t_{0}}
$$

となる． $\tilde{c}=1,2$, および, 3 の場合に, $\tilde{x}_{m}$ によつて， $c_{s}, \bar{V}$ がどのように変わるかを示した のが Fig. 7,8 である.この図から明らかなように，一般に割れ目の先端が応力 O の点を通 りすぎても急にはとまらず，およそ，分布範囲の 2 倍ほど進行してとまる。 また，応力の分 布範团が広いほど平均速度は $S$ 波の速度に近づく。 
以上, 割れ目伝播の停止条件を調べる一つの試みとして有限な応力分布について述べた。地 震学的データとの比較については, 最初に述べたような他のいくつかの場合について結果を出 したのち，発表したいと思つている。

\section{文献}

Kostrov, B.V., 1966, Unsteady propagation of longitudinal shear cracks, PMM, 30, 1241-1248.

竹内 均・菊地正幸, 1971, 割れ目の伝播, 地質工学.

菊地正幸・竹内 均, 1971， SH 型割れ目の伝播沉いて，地震 23，304-312. 